\title{
French Psychoanalyst Piera Aulagnier Concept About the Neurosis Psychopathology
}

\author{
Henrique Guilherme Scatolin \\ PUC-SP (Pontificate Catholic University of São Paulo), São Paulo, Brazil
}

\begin{abstract}
This article study object aims at the neurotic potentiality concept study proposed by Piera Aulagnier. From a literature review on this psychoanalyst work, the author highlights the neurotic potentiality as the conflict between the Self and his ideals, using the identificatory building metaphor. Over the results, it is pointed out that this French author does not discard the conflict between instances, nor the impulsive conflict, as described by Freud, noting that it is this conflict chronicity and intensity what specifies the neurotic commitment. It is concluded that the neurotic symptomatology will manifest when the neurotic Self invests in another Self because he wanted to be loved and protected, willing to satisfy his former childish demand, but thanks to the repression effect, this sexual pleasure becomes impossible.
\end{abstract}

Keywords: identificatory conflict, Self constitution, repression, children demand

From her clinical practice with psychotic patients, Aulagnier (1975) develops the potentiality concept to replace the term "structure" proposed by Jacques Lacan. When writing her book The Interpretation Violence (A Violência da Interpretação), she states: "The psychotic potentiality is... a psyche organization that cannot product manifested symptoms" (p. 177). Before writing about this work, her productions were directed, among other issues, to the maniac-depressive structure, the psychotic structure, and the perverse structure. With this book publishing in 1975, this distinguished psychoanalyst replaces the term structure by potentiality. Although she does not make a concept, at that moment, of what would be the potentiality, she only states that this would be a psychic potentiality, which could remain latent or the psychosis can arise from this. Thus, Aulagnier understands that the potentiality concept is related with something virtual, in potential, due to a psychic inclination determined in childhood, in a definition quite close to the psychic inclination approached by Freud.

In 1984, when writing The Historian Apprentice and the Wizard Master ( $O$ aprendiz de Historiador e o Mestre Feiticeiro), Aulagnier understands that potentiality concepts "include the 'possible' Self functioning and its identificatory positions, once childhood is finished" (1989, p. 228). Aulagnier understands the potentiality concept as an indentificatory position that Self will assume and the end of childhood. This means that it is at T2 point where potentiality can be established, deciding on the response and defense ways that Self can have when confronted with a conflict. Thus, it is at this moment (T2), at the moment of the conclusion time, with the assumption (or not, or partial) of castration, that the neurotic potentiality, psychotic or polymorphic definitely settles, unless the autism or a psychosis appears in childhood.

For Aulagnier, "The psychopathological phenomena totality, which we find in the clinical practice in

Henrique Guilherme Scatolin, Master, PUC-SP (Pontificate Catholic University of São Paulo). 
various forms, are the more or less disguised consequence and manifestation operating at the level of the Self investments and, therefore, in his identificatory economy" (1985, p. 18). Aulagnier understands the potentiality as identificatory conflicts, comparing the identificatory building with a puzzle. This means that when making use of a metaphor, Aulagnier points out that this puzzle fittings must be the certitude points in which the child Self will anchor. These certitude points were provided by the identified present in the parental discourse, such as the maternal, so prevalent. To these certitude points the identificants are added and by which the child is named; first, appropriating the parental discourse, to subsequently, getting certain independence.

\section{The (Un)fittings and the Identificatory Conflict}

For a better understanding of such fittings, Aulagnier emphasizes that it "is effectively the identificant relation with these certitude points present in the identified that makes it possible and preserves the symbolic identification" (1985, p. 23). For prolonging the discussion on the identificatory building idea, it should be pointed out that, for Aulagnier, the zero type (T0) is related to the baby birth, with the primary identification, extending until time one (T1), at the Self institution moment through the imaginary or speculate identification. This time (T1) marks the beginning of a new identificatory journey, extending until the time two (T2), the time to conclude, when it is expected that the symbolic identification occurs, leading to the project identification. By means of infantile sexuality repression, the castration assumption leads to the Self reshaping in terms of identificatory position, causing the puzzle pieces re-fittings. This means that, at the first set of fittings which constitute the certitude points in which Shelf had anchored, other pieces are joint, which emblems consider the expected image and invested by the look of the demands recipients, adapting to the first fittings.

Regarding such fittings, Aulagnier (1985) states:

Before approaching the "identificatory conflict"..., we consider, through an artifice, the identificant-identified relation, regardless the function the identificatory aspiration occupies... The image that is sent from Self to his own retina and the others retina is, jointly, the enunciation that he provides to these two images.... What returns to the Self as the identified that represents him, will always be different from what he expects from this present moment, in which his aspirations of yesterday materializes. And in this difference one cannot forget the role that... a mourning, a disappointment ... will have and which can affect the Self. (pp. 25-26)

This heterogeneous characteristic of Self is responsible for the conflict potentiality. This means that the weakness points of this fittings between identificant-identified, the unfitting risks and the gap between these pieces, will always be present. If this conflict occurs between the first group and the pieces added that unveil what Self is becoming, or has become, here we have a neurotic potentiality, a moment in which the conflict will occur between Self and his Ideals, causing the neurotic conflict. Thus, by understanding the potentiality as identificatory conflicts, this psychoanalyst brings new conceptions of psychopathology, where we find the psychotic potential (in which the identificatory conflict occurs inside the Self, between his identified and identificant dimensions), the neurotic potentiality, and the polymorphic potentiality (in which we have the conflict between Self and his ideals and inside Self).

\section{The Neurotic Conflict}

About the neurotic conflict, Aulagnier (1985) states:

While the conflict respects the identificant-identified unit to oppose Self and his ideals, its consequences will be less 
dramatic. The conflict, in this case, will be the identificatory aspirations coexistence, contradictory, that is, the contradiction between the current Self and what he wants or prohibits to become: this conflict is the neurosis. (p. 26)

Aulagnier, postulating that in the neurotic potentiality there is a conflict between Self and his Ideals, she does not exclude the conflict between instances, nor the impulsive conflict, as it is described by Freud, but points out that this conflict chronicity and intensity that specifies the neurotic commitment. So, over the course of her work, by agreeing with Freud conceptions on neurosis, her methodological and technical reflections become as a reference to the neurosis clinic, although she continues contributing to the other psychopathologies, including psychosis.

Aulagnier (1985) adds that, on neurotic potentiality, the "conflict concerns the investments between Self and the objects which it demands 'a plus' pleasure" (p. 138). This means that the investment in ideals is not a vital requirement, but it is necessary, at certain moments, so this Self chooses to live.

About the neurosis, she (Aulagnier, 1985) points out:

Every neurosis has its manifested form the moment in which an Oedipus complex should be dissolved, the moment in which the investment directed to the parental Selves should not disappear, but modify through a demand decantation to them directed and through the desire to find new recipients to the demands that can no longer be addressed to the parents. Repression which allows Self forget that he expected from the parents a sexual pleasure, when in fact he preserves such desire thanks to the determination that is operated.... (p. 161)

In neurosis there is an impulsive investment of Self in an expanded reality represented by a space that goes beyond the family space. The investment in a new object, in a new Self, can only come true, without a larger conflict, if Self feels confident of an agreement between this new Self and the ideal representations already invested in his past and which he cannot abandon or modify. This means that, in this extended reality, in the neurosis field, we can find an old demand that was addressed to the parents being aimed at new people, although there is Self ignorance about the sexual component neurotic included in this demand to his replacements. So, the answer the neurotic receives from this demand cannot satisfy what it is covered behind the apparent legitimacy of pleasures that this Self conjectures to ask.

In relation to this reply intended for other people, Aulagnier (1985) also falls back to repression failure, pointing out:

The neurotic symptomatology blooms when Self invested the Self of another because he thought so to satisfy his childhood demand, what proves that he only changed the recipient, without then modifying what he expected in response to his first demands: to be loved, protected, as he wanted to be loved and protected by his parents and, moreover, that give him sexual pleasure. (p. 161)

On neurosis, the demand addressed to another becomes utopian, because the other cannot be, at the same time, mother and sexual partner, as well as the father cannot become his lover, and the son (or daughter) his pleasure object. All this happens thanks to the repression effect. Thus, the neurotic symptomatology will manifest when Self invests in another Self because he wanted to be loved and protected, willing to satisfy his former childish demand, but thanks to the repression effect, this sexual pleasure becomes impossible.

For Aulagnier (1989), "By the neurosis side, T2 matches the assumption by Self of a symbolic position that he can preserve and respect" (p. 234). At this point, the neurotic conflict lies in the imaginary registry and the aggregated pieces choice. This means that the neurotic continues to project on his successive identified the shadow of that, which is supposedly the only one who can attract into his advantage a love that he could repeat 
the same love expected and required in his remote childhood, but due to repression (secondary), such fact cannot be conceived.

For this psychoanalyst, the secondary repression goal is "to exclude from the Self space certain impulsive representations which representation is incompatible with cultural requirements that cannot be infringed, and with identificatory positions that are the only ones that can allow the Self to perform a portion of his desires, his demands, and his goals" (Aulagnier, 1989, p. 267). Due to this secondary repression, we found the incest and patricide interdict. This means that the interdictions pronounced by the parental instance became a megaphone of cultural requirements. These interdicts are already present in the parents repressed, i.e., in the desire to which they renounced in their remote childhoods.

Aulagnier (1990) points out that, "In the neurosis registry, the suffering essential cause the presence of a desire that we cannot or that we interdict to perform, at the same we refuse to renounce it" (p. 296). In the neurosis, as desire is related to oedipal object, its resignation is seen by the neurotic as the eventual disappearance of all desire. Consequently, the neurotic transformed into suffering causes a child investment and it still remains as a source of pleasure. Therefore, preserving the investment in other people, the neurotic creates a false illusion of his suffering disappearance.

This suffering, to Aulagnier (1990), "protects the subject of a persecutory relationship" (p. 228). It is the system itself and the neurotic commitment to adopt the suffering of a relational function in which we find his non-sharing, imposing to the neurotic, what Aulagnier calls the "absolute solitude experience" (1990, p. 298). And it is in this solitude experience that many obsessive neurotics keep their obsessive thoughts, their secret rituals, and other symptoms, under lock and key.

But after all, how does this distinguished psychoanalyst understand the neurotic symptom concept? Aulagnier (1985) defines neurotic symptom as "a compromise between the repression and the Self repressor action, after a first failure, that tries to control what returns, and creates a barrier that protected him against this irruption" (p. 17). That is, the neurotic symptomatic construction refers to the identicatory conflict existing in the space between Self and his Ideals. So, it is this conflict chronicity, presented in the neurotic symptom, which will specify the neurosis intensity.

According to Aulagnier (1990), "Whatever the neurotic symptomatology is, its center always reveals an identificatory conflict. It is proper to the neurotic Self to be taken by an unsustainable doubt concerning his truth and his affections" (p. 236). This quote matches this thesis problematic. Namely, when pointing that in all neurotics symptomatic center there is an identificatory conflict, Aulagnier points out an intrinsic relation between symptomatic formation and the identificatory problem. In addition, here it is highlighted that the importance given to the neurotic symptomatology doubt, since Self is already sentenced to doubt and not to fall into the certitude abyss.

If the ability to doubt is linked to the thinking activity, Aulagnier (1985) points out that the neurotic "can... preserve the thought functioning, preserve creativity and the resulting pleasures, and, often, super invest this pleasure" (p. 161). It is in the neurotic pathologies that the thinking and investing functions are compromised, and the right to choose the thoughts that communicate and those which he keeps secret is a vital condition for the Self proper functioning.

In the neurosis "having to think, having to doubt the thought, having to check it; these are requirements to which Self cannot avoid, the price at which he pays his citizenship right in the social field and his participation in the cultural adventure" (Aulagnier, 1990, p. 271). The self learned quickly that thinking is a necessary work 
and comprises many evidences, causing pleasure and displeasure. So, think and invest denominate two functions without which the Self could not accrue, or preserve his space in the psychic scene, and the suffering, displeasure, is the price that they should pay for his existence.

For Aulagnier (1990), "The neurotic will actually have the inclination, during the session, to mainly invest 'transference thoughts', he will rarely think of a 'pink cloud' by the sole pleasure of his having this thought" (p. 277). And the neurotic subject Self should be able to oppose his pleasure or displeasure right inalienability about certain thoughts, determining his right to secretly think and experience pleasure or displeasure with it. Remember that a necessary condition to the Self functioning is present in the fact that he could exercise his right to think and enjoy on his own thought activity. On neurosis, even if the thinking freedom is not unlimited, all its forms are characterized by a partial loss of that thought freedom due to the repression action. Consequently, the exclusion of a number of thoughts becomes possible at the expense of Self thought activity impoverishment, of a loss of power to think without locks. Thus, we find here one of the neurotic suffering reasons: the intellectual inhibition.

Beyond the intellectual inhibition, on neurosis, the subject can:

Preserve the thought functioning, preserve the creativity and the pleasures that result from them and, often, super invest this pleasure...; we know it can preserve friendships and professional relations and only conflict with the beloved relationship, with the one he wanted to love or the one whose love is not according to what he himself defines by this term. (Aulagnier, 1985, pp. 161-162)

It is in this conflict that pleasure becomes random or impossible. Due to this impossibility, an aggressiveness part unties from the sexual and looks for his achievements in the external environment, whether through an aggressive behavior towards the other, or through self-aggressiveness. Thus, this aggressiveness emerges from the refusal of the other to the expected pleasure.

Regarding this aggressiveness, Aulagnier (1985) adds that "in the neurosis the impulse to death can only succeed because Self refuses the suffering cause by the absence of a pleasure to which he does not want to renounce, although the eventual realization of such pleasure implies the guilt of having transgressed the incest prohibition" (p. 162). On neurosis, the impulsive implication only becomes possible if Eros, the life impulse, finds "the objects" which can be invested. On the other hand, the aggressive response the neurotic directs to the other or to himself is, ultimately, due to the impossibility of, simultaneously, perform the incest and renounce the incestuous desire, being the guilt a result of this impossibility.

\section{Conclusion}

From the literature review, this article brought the neurotic potentiality concept, noting that, although Aulagnier has a clinical experience more aimed at the psychosis field, she also left a legacy to the neurosis field, connecting it to the repressed childhood desires manifestations, being the conflict intensity between Self and his Ideals what will define the neurotic conflict. In this field, there is a former childish demand of these children desires being aimed at new people, although there is an ignorance of the sexual component neurotic Self included in this demand. Therefore, this article is completed highlighting that the neurotic symptomatology will manifest when the neurotic Self invests in another Self because he wanted to be loved and protected, willing to satisfy his former childish demand, but thanks to the repression effect, this sexual pleasure becomes impossible. 


\section{References}

Aulagnier, P. (1975/1979). A violência da interpretação: Do pictograma ao enunciado. Tradução de Maria Clara Pellegrino. Rio de Janeiro: Imago.

Aulagnier, P. (1979/1985). Os destinos do prazer. Rio de Janeiro: Imago.

Aulagnier, P. (1984/1989). O aprendiz de historiador e o mestre feiticeiro: Do discurso identificante ao discurso delirante. Tradução de Claudia Berliner. São Paulo: Escuta.

Aulagnier, P. (1986/1990). Um intérprete em busca de sentido-I. Tradução de Regina Steffen. São Paulo: Escuta. 